\title{
Re-evaluating superelevation in relation to drainage requirements and vehicle dynamics
}

\author{
D. B. Chaithoo \& D. Allopi \\ Durban University of Technology, \\ Department of Civil Engineering and Surveying, \\ Faculty of Engineering and The Built Environment, South Africa
}

\begin{abstract}
There is a growing public demand for safer streets and highways. Designing safer roads requires a need to review and improve the existing design guidelines. Road widening and general roadway rehabilitation projects are designed according to the existing roadway conditions. As a result, drainage problems associated with superelevation are prevalent. An evaluation of design alternatives in terms of safety, taking into consideration the superelevation values in relation to the drainage requirements and vehicle dynamics, will prolong the design process. However, it is believed that the additional time invested will result in safer roads and a reduction in vehicular accidents and in addition a potential in lower construction costs. This latter benefit is derived by limiting instances where a design component is overdesigned.

The objectives of this paper is to (1) develop drainage criteria for flow paths and depths on road surfaces due to superelevation, (2) analyse the speed and vehicle dynamics at sharp or reduced horizontal curves, (3) develop superelevation criteria for steep longitudinal grades on sharp horizontal curves by identifying and analyzing associated drainage problems and (4) present an overview of an independent software tool to assist geometric designers and authorities in the civil engineering industry to design 'safe' roads from a geometric design viewpoint by taking factors such as time, cost, quality and context-sensitive design solutions into consideration. The paper draws from an innovative desktop literature analysis study and presents an overview of the research objectives. The desktop study is complemented by the analyses of data from user and stakeholder samples conducted on a section identified on National Route 3.
\end{abstract}


Various physical and theoretical methods of analysis are described in the paper and the ultimate observations and findings will be published in a geometric design manual. The software tool simulates the stormwater drainage flow path in relation to the design superelevation criteria values assessed and evaluated to prevent hydroplaning. The resulting outputs will present a theoretical review of the geometric design considerations involved.

The South African Minister of Transport reiterated that we need to prevent the number of accidents on our roads and this paper seeks to persuasively identify a solution from a geometric design perspective. We need to design safer roads.

Keywords: superelevation, drainage, vehicle dynamics, hydroplaning, geometric, water flow depth.

\section{Introduction}

\subsection{What motivates the research paper?}

\subsubsection{Safety scene}

It is a well known fact the road accidents in South Africa are a serious cause of concern. According to the latest traffic accident statistics over the past three years as depicted in Figure 1, there has been a substantial number of fatalities.
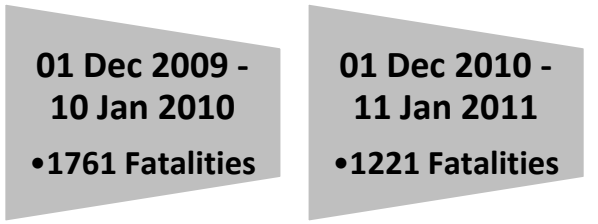

\section{Dec 2011 - \\ 10 Jan 2012 \\ -1230 Fatalities}

Figure 1: $\quad$ Festive period fatality figures - December 2009 [1] - January 2012 [2].

\subsubsection{Van Reenen's Pass on National Route 3 (N3)}

Van Reenen's Pass is one of the most beautiful sections of the N3 between Johannesburg and Durban. Transcending the escarpment between the Free State and Kwazulu-Natal, Van Reenen's Pass is a milestone in any journey along the N3. It offers a superb view of the surrounding countryside and the World Heritage Drakensberg Mountain range.

But the pass has a dark side. The road is steep, very steep in places and twists and turns as it follows the rugged terrain. The weather is infamously fickle, with high winds capable of blowing caravans and light trucks onto their sides. Snow has on a number of occasions completely closed the road, while mist and rain regularly reduce visibility and render the road treacherously dangerous. As the economy continues its robust growth, traffic has significantly increased, in particular heavy vehicles. Trucks relentlessly grind up and down the pass day and night. The speed differential between trucks in low gear and the powerful new generation of light vehicles is alarming in both directions. Close to a third of all vehicular traffic are large trucks. 
High speed differentials and failure to adapt speed in relation to circumstances are a recipe for accidents. Holiday periods are generally in the rainy season and road elements, especially drainage, contribute to accidents.

As part of the ongoing commitment towards road safety, convenience and mobility, N3TC conducted a comprehensive road safety audit in 2006, [3], which highlighted speed as the main cause of accidents at various locations along the N3 between Cedara and Heidelberg. Sections where speed limits are posted necessitate patience, appropriate reductions in speed and full concentration on the part of drivers. The results do not portray a pretty picture and from a road safety point of view, Van Reenen's Pass is the single most dangerous section of the N3.

N3TC has identified and addressed road safety on Van Reenen's Pass from three points of view, namely engineering, education and enforcement [4].

N3TC has implemented interventions to reduce the number of accidents on the pass but currently the greatest causes of accidents is by vehicle unfitness, rear-end collisions due to high speed differentials, dangerous inter-lane manoeuvres and driver disorientation in adverse weather conditions.

\subsubsection{Superelevation - the problems associated with roadway cross slopes}

There are varying viewpoints and opinions among civil engineering professionals on the usage of the superelevation values given in the TRH17 [5] and SANRAL's Geometric Design Guidelines [6]. The geometric design considerations need to be reviewed especially when it relates to road surface drainage at points where the road has no crossfall during development of superelevation.

Currently the SANRAL Drainage Manual, 5th Edition, pp. 5-2 [7] recommends that the flow depth during a 1:5 year storm should not exceed $6 \mathrm{~mm}$. This is in contrast to the Design of Urban Highway Drainage Manual (FHWATS-79-225) [8] recommendations and an example provided in the Urban Drainage Manual, pp. 4-4 [9]. Hydroplaning can occur at speeds of $89 \mathrm{~km} / \mathrm{h}$ with a water film depth of $2 \mathrm{~mm}$. According to the Highway Surface Design Manual [10], the critical depth for hydroplaning ranges from $4 \mathrm{~mm}$ to $10 \mathrm{~mm}$ depending on tyre and pavement surfacing. The surface water depth therefore, should be restricted to $4 \mathrm{~mm}$ for all but special situations where superelevation produces long, curved flow paths. There are three common special situations where surface water depth may become critical, namely, horizontal alignment curvature, intersections and ramps and superelevation development.

\subsubsection{Hydroplaning}

Hydroplaning is a phenomenon characterised by a complete loss of directional control when the tyres are moving fast enough that it rides up on a film of water and thereby loses contact with the pavement. A general rule of thumb for rural highways is that hydroplaning can be expected for speeds above $72 \mathrm{~km} / \mathrm{h}$ where water ponds to a depth of $2.5 \mathrm{~mm}$ or greater over a distance of $9 \mathrm{~m}$ or greater. The probability of hydroplaning occurs when vehicle, roadway and environmental factors are taken into consideration. For any set of driver inputs and tyre conditions, hydroplaning is a function of water flow depth. 
Accidents involving hydroplaning became more apparent as roadway speeds increased, wider pavements, in particular asphalt pavements, being built, and greater pavement wear due to the increase of traffic volumes and heavier loads. Although hydroplaning is a very complex phenomenon, it is associated with several factors. The likelihood of hydroplaning on wet pavements increases with roadway and environmental factors that increase water flow depth and with driver and vehicle dynamic factors that increase the sensitivity to water flow depth as depicted in Figure 2.

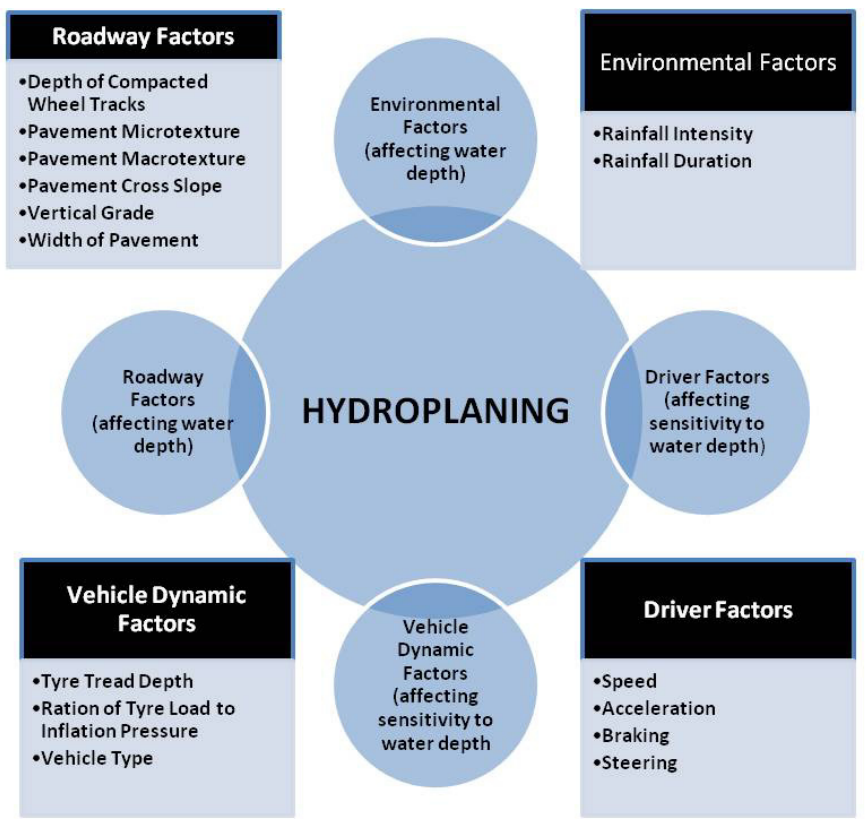

Figure 2: Hydroplaning factors.

\subsection{Why is the research being undertaken?}

\subsubsection{Criteria}

Criteria for superelevation where steep vertical grades have a direct effect on drainage on horizontal curves have not been developed according to the TRB Research in Progress website [11]. Drainage problems associated with superelevation has resulted in an increase (especially at road widenings) in vehicular accidents and a thorough study of the surface water flow paths and water flow depths on road surfaces due to superelevation requirements needed to be further investigated, researched and analysed. The analysis and context of this paper identifies the factors such as speed affecting the vehicle dynamics at sharp or reduced horizontal curves where flow paths of surface water are problematic and can lead to hydroplaning. Driver behaviour during hydroplaning in conjunction with the geometric design of the roadway was a factor considered 
during the research. This study was completed under heavy vehicular traffic conditions during adverse weather conditions.

\subsubsection{How will the results add to the body of knowledge?}

The TRH17 document was compiled to be a design guideline for the geometric design of rural roads in preference to standards. An objective of the TRH17 was to continuously amend the draft document, through consultation between the authorities, discussion with practitioners and ongoing research. This has not happened. It is common practice by geometric designers to use the TRH17 document for the design of rural roads without questioning the values obtained in the tables and graphs. The validity of the guidelines should be judged by the geometric designer in each specific situation as well as the consequences of departing from the values suggested.

Similarly SANRAL's Geometric Design Guidelines have been developed to assist design consultants. The originations of the guidelines stem from AASHTO [12]. Currently there are no standards developed for SA and these guidelines are authority specific.

\section{Elements affecting safety at superelevation}

The drainage conditions of the roadway in relation to the vehicle dynamics needed to be further investigated as superelevation along sharp horizontal curves with reduced sight distances presents a significant level of driver concentration. The driver tends to correct the vehicular path. The surface stormwater run-off flow path along the horizontal curve effects natural braking forces which in turn can lead to hydroplaning. The theoretical analysis indicated that the potential for hydroplaning is sensitive to water flow depth.

During high intensity rainfall events, a water film builds up on the surface on the road. The risk of vehicle hydroplaning increases as the depth of this film increases. The loss of steering and drag force produced during hydroplaning may then cause the vehicle to lose control, especially when a steering tyre is involved. Rainfall intensity is the most important environmental factor in hydroplaning.

The risk of dynamic hydroplaning is directly proportional to the depth of water in the road surface. This depth is affected by a wide range of factors that are contributed to by the environment such as the geometric design, pavement design, drainage design and maintenance and by the condition of the vehicle. The geometry of the road has a large effect on the water depth and is the factor over which the geometric designer has the most control. The length of time water is able to stay on the road will influence the depth it achieves. Longer flow paths mean more time to accumulate rainfall and result in higher flow depths. Changes in superelevation, reduced horizontal alignment and sag curves are some of the problem areas where the slope is low or where water has to flow a long way over the pavement before being intercepted by a drainage system or dissipating into the adjacent terrain. Superelevation changes can result in long curving flow paths which may be problematic. Steeper longitudinal slopes can also increase the flow path length and resulting depth. 
The pavement texture depth affects the water depth by allowing some of this water to flow between the aggregate or in grooves providing flow paths to allow water in front of the tyre to be forced out under pressure. Porosity can also be considered as some pavements such as open-graded porous asphalt allow water to drain through them, taking it away from the surface. Wheel track depressions have a significant effect on the drainage patterns increasing water depth and concentrating flow. The N3 has varying pavement surfacing of which further analysis will be done considering the friction factors and drainage flow path on these surfaces.

Pavement drainage solutions are essential to ensure that no water is able to pond on the trafficable road surface, particularly in sag areas. This is vital in order to reduce the hydroplaning risk. Vehicle characteristics and behaviour are also important factors in hydroplaning. The speed at which a vehicle needs to travel to begin hydroplaning is determined by water flow depth but also by the vehicle's weight and tyre characteristics. The vehicle weight determines how much uplift force is needed to induce separation and it follows that a lighter vehicle will hydroplane at a lower speed. Higher tyre pressures increase the hydroplaning speed by reducing the contact area between tyre and road, increasing the vehicle's weight to area ratio. Tyre tread depth also affects hydroplaning the same way as pavement texture, with deeper tread moving the water away from the area of contact more effectively. While minimum tyre tread depth and maximum speed are both specified by law, minimum weight and tyre pressures are not. These are vehicle manufacturer recommendations specific.

In summary, drainage requirements versus vehicle dynamics are the key factors considered in the development of superelevation criteria at reduced horizontal curves to minimize hydroplaning on the N3. Practical considerations such as tyre tread depth, pavement characteristics and drainage solutions were evaluated along the route.

\section{Research background}

Significant roadway degradation such as polishing of aggregates, bleeding of bitumen and rutting depletes the friction supply available for cornering. This depletion results from the use of a portion of the friction supply to provide the necessary braking force required to maintain speed on the downgrade. The speed of the vehicles and the vehicle dynamics have been analysed as differing vehicles have different friction forces exerted on the roadway. It cannot be assumed that the relevant design criteria for a car are similar to that of a truck or vice versa. Skid marks are significantly prevalent and N3TC/SANRAL/DoT accident reports will need to be investigated as part of the research study. These reports were not made available due to the legal nature of the relevant data acquisition.

It is noted from the TRH17 that the design vehicle is a single unit truck. This undesirable combination results in a significant decrease in the margin of safety resulting from roadway grade, especially for heavy vehicles. On long or fairly steep grades, drivers tend to travel faster in the downgrade than in the upgrade direction. Additionally, research has shown that the side friction demand is 
greater on both downgrades (due to braking forces) and steep upgrades (due to the traction forces). Downgrades on horizontal curves may be problematic, and that adjustment for it may be desirable in some cases.

There are no guidelines as to how this adjustment should be made for two lane or multilane divided or undivided roadways. Some adjustment in superelevation rates should be considered for grades steeper than 5\%. This adjustment is particularly important on roadways with high truck volumes and on low-speed roadways with intermediate curves using high levels of side friction demand. The superelevation revision proposition highlights that this adjustment be made by using higher design speeds criteria for the geometric design of the roadway. More definitive guidance on this adjustment, as well as adjustment for other elements of the horizontal curve, is needed. The design speed versus minimum curve radii of horizontal curvature needed further investigation to ensure safety on sharp horizontal curves taking the other related factors, like superelevation, into consideration.

The article published in the Pretoria News, "Wet weather causes a spike in road accidents" [13] referred to the significant increase in roadway accidents during rainy weather. The drainage requirements and vehicle dynamics in relation to superelevation design of the roadway was therefore investigated and researched. One of the major findings was that pavement cross slope was a dominant factor in draining water from the pavement surface. A theoretical evaluation was done to emphasize the importance of drainage path length as a function of both cross slope and longitudinal grade. It was found that the drainage flow path length and water flow depth increases with pavement width and longitudinal grade, and decreases with cross slope.

Various professional engineers, technologists and independent consultants were consulted in the transportation industry. The responses received were favorable in terms of the need for further investigations of superelevation in relation to drainage requirements and vehicle dynamics for roadway geometric design.

\section{Research objectives and methodology}

The primary objective of this paper was to identify improved methods for draining rainwater from the surface of the pavement by re-evaluating superelevation in relation to drainage requirements and vehicle dynamics. The research methodology for the paper is highlighted in Figure 3.

\subsection{Research problems and aims}

Various sections of the N3 are being upgraded or rehabilitated to improve the quality and lifespan of the road due to vehicular traffic increases. There is significant freight movement. This has resulted in an increase in vehicular accidents. The viewpoint on the design considerations adopted on the N3 is subjective as driver safety factors and other mitigating risks of vehicular accidents need to be further investigated. 


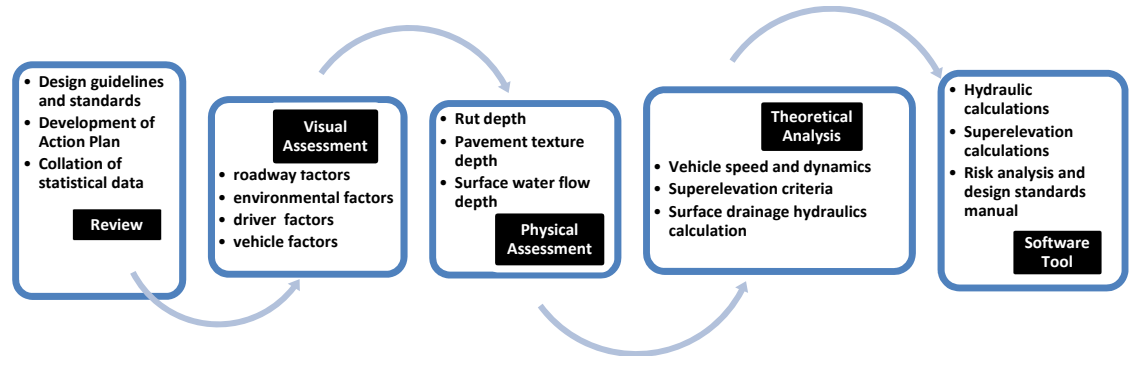

Figure 3: $\quad$ Research methodology.

From a geometric design analysis viewpoint, road-widening and general roadway rehabilitation are designed according to the existing roadway conditions and drainage problems associated with superelevation is prevalent. Ponding has been recorded and visual evidence is prevalent in certain areas. The general stormwater design criteria should be viewed and analysed differently from the Kwazulu-Natal conditions as opposed to the Free-State and Gauteng conditions as the runoff rainfall intensity and time of concentration varies significantly.

The aim is to develop a standard design manual and software tool to assist geometric designers and authorities by theoretical and desktop analysis of:

- $\quad$ superelevation criteria at steep gradients with sharp horizontal curves;

- drainage flow path lengths and water film depths on road surfacing;

- $\quad$ speed and vehicle dynamics;

- improved methods for draining rainwater from the surface of pavements.

\section{Research outcomes}

Based on research findings and in consideration of pavement irregularities (settlements, rutting, etc), it is recommended that a minimum of $2.5 \%$ cross slope be implemented as a design criteria to minimise the propensity of hydroplaning.

The objective of this paper is also not to minimise the importance of factors such as tyre tread depth, tyre pressure and vehicle speed in contributing to the probability of hydroplaning but rather to highlight that a significant portion of the driving population either drives vehicles with barely legal tyre tread depth, or maintaining optimum tyre pressure, and/or are often uninformed about reasonable reductions in normal speed during adverse weather conditions.

\subsection{Loss of skid resistance caused by pavement defects}

Once it has been determined that an accident was the result of hydroplaning, it is important to determine the construction history of the accident area and if the pavement surfacing was the causal factor. Roadway maintenance and 
improvements can significantly alter the pavement surface and composition as noted on the N3.

The depths of the ruts are measured, if present, plus any other accident scene measurements should be taken during an accident reconstruction investigation if the accident scene has not been altered significantly. All pavement samples taken for testing for defects must be considered legal evidence. Irregular cross slopes and rutted wheel paths, especially at the beginning and end of horizontal curves, cause water to collect and flow in the wheel paths.

Proper design, construction and vigilant maintenance of the cross slopes, and superelevation of the high speed roadway, will go a long way to guard against the unintentional results of excessive water on the pavement surface.

The exact point at which hydroplaning occurs is complicated and depends on all of the following variables:

- Tyre size - the size and shape of a tyre's contact area has a direct influence on the probability to hydroplane. The wider the contact area is relative to its length, the higher the speed required to support hydroplaning.

- Tyre tread pattern - certain tread patterns channel water more effectively and varies with tyre manufacturer's specifications.

- Tyre tread depth - as tyres become worn, their ability to resist hydroplaning is reduced. The legal tread depth of $1.6 \mathrm{~mm}$ should be regulated to $3 \mathrm{~mm}$ to increase the braking distance.

- Tyre pressure - keep tyre pressure within the manufacturer's recommendations.

- Water depth - the deeper the water, the quicker to lose traction, although at higher speeds even thin water layers can cause a loss of traction.

- Water composition - oil, temperature, dirt and salt can change the properties and density of the surfacing.

- Vehicle drive-train - due to computer-assisted differentials, all-wheeldrive vehicles are more likely to hydroplane than two wheel drive vehicles in certain situations. A sudden uncontrolled transfer of power from the front tyres to the rear tyres can put a hydroplaning all-wheeldrive vehicle out of control.

- Vehicle speed - as speed increases, wet traction is considerably reduced. Reduce speed since hydroplaning can result in a complete loss of traction and vehicle control.

- Vehicle weight - the lighter the vehicle, the more likely it is to hydroplane. It is noted from vehicle sales statistics that a large percentage of new vehicle sales are light vehicles.

- $\quad$ Road surfacing type - non-grooved asphalt is considerably more hydroplane-prone than ribbed concrete surfacing. 
Water sheeting should not be confused with ponding water. Water sheeting is due to runoff travelling across the surface in an unconstrained environment. Ponding water occurs when this sheet flow becomes constrained in vehicle wheel paths, etc. The consequences of vehicles striking ponded water are typically loss of control due to an imbalance in forces on each side of the vehicle. This is not the same situation as hydroplaning and may occur at much lower speeds.

Table 1 indicates the various factors, their method of control and potential influence by highway designers and driver behaviour.

Table 1: $\quad$ Influences on skid resistance on wet roads.

\begin{tabular}{|c|c|c|}
\hline Factor & Control & Influenced by \\
\hline Water depth & $\begin{array}{c}\text { Weather Conditions } \\
\text { Geometric Design } \\
\text { Guidelines }\end{array}$ & $\begin{array}{c}\text { Other } \\
\text { Design Engineer }\end{array}$ \\
\hline Road Surface Microtexture & $\begin{array}{c}\text { Geometric Design } \\
\text { Guidelines }\end{array}$ & Design Engineer \\
\hline Road Surface & $\begin{array}{c}\text { Geometric Design } \\
\text { Guidelines }\end{array}$ & Design Engineer \\
Macrotexture & Maintenance Standards & Design Engineer \\
\hline Road Surface Condition & $\begin{array}{c}\text { Road Layout } \\
\text { Legislation }\end{array}$ & $\begin{array}{c}\text { Design Engineer } \\
\text { Driver Behaviour }\end{array}$ \\
\hline Vehicle Speed & Legislation & Driver Behaviour \\
\hline Tyre Tread Depth & Legislation & Driver Behaviour \\
\hline Type Wear & $\begin{array}{c}\text { Manufacturer's } \\
\text { Specifications }\end{array}$ & Driver Behaviour \\
\hline Type Pressures & Manufacturers & Other \\
\hline Vehicle Specifications & Manufacturers & Other \\
\hline Type Materials & Manufacturers & Other \\
\hline Tyre Tread Pattern & \multicolumn{2}{|c}{} \\
\hline
\end{tabular}

\subsection{How to avoid or minimise skid resistance caused by insufficient drainage gradient}

Roads should be designed in such a way that sections where the cross slope change direction (superelevation) is located where the road is going uphill or downhill. Alternatively the pavement will get an area with minimal drainage gradient $(<0.5 \%)$, resulting in unacceptable skid accident risk.

When designing road curves in a flat landscape (areas noted are between Harrismith and Wilge Toll Plaza), it may be necessary to design long wave undulations on purpose. These 'synthetic' longitudinal gradients can then be used to reach a sufficient drainage gradient, in sections where the cross slope is close to zero.

The depth of water on a roadway surface, for a given intensity of rainfall, depends on the distance and gradient along the flow path. The flow path is the route taken by rainfall runoff from the point at which it falls on the roadway surface to the roadway edge. For a roadway with no longitudinal gradient flow paths will be transversed to the direction of travel. As the longitudinal gradient 
increases the flow paths will become diagonal. Flow path lengths and gradients will be determined by the combination of roadway width, carriageway crossfall and longitudinal gradient.

For evaluation purposes, the flow path is the maximum distance taken by runoff in reaching the edge of the roadway. For wide roadways, as in the case of the N3, the most direct drainage flow path, and therefore the shortest flow path lengths, occur at zero longitudinal gradients. Surface water can quickly infiltrate the roadway surfacing, greatly increasing the amount of free surface water, which causes splash and spray from the vehicle tyres. This increase in splash and spray reduces visibility, resulting in unsafe roadway conditions. With the surface water infiltrating the pavement surfacing, the reflections of vehicle headlights are greatly reduced and the visibility of roadway markings is increased.

\section{Conclusion and recommendations}

Thirty-nine people have been killed each day on South Africa's roads. This is an unaccepted phenomenon which must be investigated and solutions to be developed and adopted. According to RTMC the following are noted as the most common causes of crashes:

- Speeds too high for circumstances, especially during inclement weather and at night;

- Dangerous, reckless and/or inconsiderate driving, particularly barrier line infringements which has seen a huge increase in fatalities as a result of head-on type collisions. More than $70 \%$ of the major fatal crashes were of the head-on type as a result of dangerous overtaking;

- Abuse of alcohol by drivers and pedestrians;

- Fatigue, especially amongst public passenger drivers;

- Vehicle fitness, particularly tyre failure and defective brakes; and

- Pedestrian negligence (jay walking, walking on freeways, not visible at night and drunken walking).

This paper has deduced that accidents caused by current geometric design guidelines needed to be further investigated as certain mitigating geometric design factors are overlooked. Pavement cross slopes (superelevation) are a compromise between drainage (steep slopes) and driver comfort and safety (flat slopes). This was prevalent when analysis of the water flow length relationship to flow path slope, flow path length, surface texture depth and rainfall intensity were theoretically calculated. The software tool is currently under review in order to develop the computer model and design standards. The design standards and associated software tool will allow the design engineer to select the pavement geometry that minimise sheet flow; to select and locate drainage appurtenances; and to select various mixture types and surface textures that will also minimise water film thickness and the potential for hydroplaning.

A summary of the surface drainage calculations (Tables 2-4) was done using the software tool highlights that water flow depth reaches the recommended flow depth of $4 \mathrm{~mm}$ which, when combined with hydroplaning factors, leads to an unsafe roadway design. The hydraulic calculations were done in accordance with 
Table 2: $\quad$ Surface drainage calculations - 2-lane, 2-way rural roadway.

\begin{tabular}{|c|c|c|c|c|c|c|c|c|}
\hline$\frac{2 \text { lane } 2 \text { way rural }}{\text { roadway }}$ & & & & & & & & \\
\hline Road crossfall (\%) & 2.00 & 2.00 & 2.00 & 2.00 & 2.00 & 2.00 & 2.00 & 2.00 \\
\hline Road gradient (\%) & 1.00 & 2.00 & 3.00 & 4.00 & 5.00 & 6.00 & 7.00 & 8.00 \\
\hline Width of roadway (m) & 13.40 & 13.40 & 13.40 & 13.40 & 13.40 & 13.40 & 13.40 & 13.40 \\
\hline Rainfall intensity $(\mathrm{mm} / \mathrm{h})$ & 80.00 & 80.00 & 80.00 & 80.00 & 80.00 & 80.00 & 80.00 & 80.00 \\
\hline Calculation results & & & & & & & & \\
\hline Flow path slope (\%) & 2.24 & 2.83 & 3.61 & 4.47 & 5.39 & 6.32 & 7.28 & 8.25 \\
\hline Flow path length (m) & 14.98 & 18.95 & 24.16 & 29.96 & 36.08 & 42.37 & 48.78 & 55.25 \\
\hline Flow depth (mm) & 3.41 & 3.65 & 3.93 & 4.19 & 4.43 & 4.65 & 4.85 & 5.04 \\
\hline Road crossfall (\%) & 2.50 & 2.50 & 2.50 & 2.50 & 2.50 & 2.50 & 2.50 & 2.50 \\
\hline Road gradient (\%) & 1.00 & 2.00 & 3.00 & 4.00 & 5.00 & 6.00 & 7.00 & 8.00 \\
\hline Width of roadway (m) & 13.40 & 13.40 & 13.40 & 13.40 & 13.40 & 13.40 & 13.40 & 13.40 \\
\hline Rainfall intensity $(\mathrm{mm} / \mathrm{h})$ & 80.00 & 80.00 & 80.00 & 80.00 & 80.00 & 80.00 & 80.00 & 80.00 \\
\hline Calculation results & & & & & & & & \\
\hline Flow path slope (\%) & 2.69 & 3.20 & 3.91 & 4.72 & 5.59 & 6.50 & 7.43 & 8.38 \\
\hline Flow path length (m) & 14.43 & 17.16 & 20.93 & 25.28 & 29.96 & 34.84 & 39.84 & 44.92 \\
\hline Flow depth (mm) & 3.22 & 3.39 & 3.60 & 3.81 & 4.01 & 4.20 & 4.37 & 4.53 \\
\hline Road crossfall (\%) & 3.00 & 3.00 & 3.00 & 3.00 & 3.00 & 3.00 & 3.00 & 3.00 \\
\hline Road gradient $(\%)$ & 1.00 & 2.00 & 3.00 & 4.00 & 5.00 & 6.00 & 7.00 & 8.00 \\
\hline Width of roadway $(\mathrm{m})$ & 13.40 & 13.40 & 13.40 & 13.40 & 13.40 & 13.40 & 13.40 & 13.40 \\
\hline Rainfall intensity $(\mathrm{mm} / \mathrm{h})$ & 80.00 & 80.00 & 80.00 & 80.00 & 80.00 & 80.00 & 80.00 & 80.00 \\
\hline Calculation results & & & & & & & & \\
\hline Flow path slope (\%) & 3.16 & 3.61 & 4.24 & 5.00 & 5.83 & 6.71 & 7.62 & 8.54 \\
\hline Flow path length (m) & 14.12 & 16.10 & 18.95 & 22.33 & 26.04 & 29.96 & 34.02 & 38.16 \\
\hline Flow depth (mm) & 3.09 & 3.21 & 3.37 & 3.54 & 3.71 & 3.87 & 4.02 & 4.16 \\
\hline
\end{tabular}

Table 3: $\quad$ Surface drainage calculations - 4-lane, 2-way rural roadway.

\begin{tabular}{|c|c|c|c|c|c|c|c|c|}
\hline \multicolumn{9}{|c|}{$\begin{array}{l}\text { SURFACE DRAINAGE CALCULATIONS } \\
\end{array}$} \\
\hline$\frac{4 \text { lane } 2 \text { way rural }}{\text { roadway }}$ & & & & & & & & \\
\hline Road crossfall (\%) & 2.00 & 2.00 & 2.00 & 2.00 & 2.00 & 2.00 & 2.00 & 2.00 \\
\hline Road gradient $(\%)$ & 1.00 & 2.00 & 3.00 & 4.00 & 5.00 & 6.00 & 7.00 & 8.00 \\
\hline Width of roadway $(\mathrm{m})$ & 20.80 & 20.80 & 20.80 & 20.80 & 20.80 & 20.80 & 20.80 & 20.80 \\
\hline Rainfall intensity $(\mathrm{mm} / \mathrm{h})$ & 80.00 & 80.00 & 80.00 & 80.00 & 80.00 & 80.00 & 80.00 & 80.00 \\
\hline Calculation results & & & & & & & & \\
\hline Flow path slope (\%) & 2.24 & 2.83 & 3.61 & 4.47 & 5.39 & 6.32 & 7.28 & 8.25 \\
\hline Flow path length (m) & 23.26 & 29.42 & 37.50 & 46.51 & 56.01 & 65.78 & 75.71 & 85.76 \\
\hline Flow depth (mm) & 4.24 & 4.55 & 4.90 & 5.22 & 5.52 & 5.80 & 6.05 & 6.28 \\
\hline Road crossfall (\%) & 2.50 & 2.50 & 2.50 & 2.50 & 2.50 & 2.50 & 2.50 & 2.50 \\
\hline Road gradient (\%) & 1.00 & 2.00 & 3.00 & 4.00 & 5.00 & 6.00 & 7.00 & 8.00 \\
\hline Width of roadway (m) & 20.80 & 20.80 & 20.80 & 20.80 & 20.80 & 20.80 & 20.80 & 20.80 \\
\hline Rainfall intensity $(\mathrm{mm} / \mathrm{h})$ & 80.00 & 80.00 & 80.00 & 80.00 & 80.00 & 80.00 & 80.00 & 80.00 \\
\hline Calculation results & & & & & & & & \\
\hline Flow path slope (\%) & 2.69 & 3.20 & 3.92 & 4.72 & 5.59 & 6.50 & 7.43 & 8.38 \\
\hline Flow path length (m) & 22.40 & 26.64 & 32.49 & 39.25 & 46.51 & 54.08 & 61.84 & 69.73 \\
\hline Flow depth (mm) & 4.01 & 4.23 & 4.49 & 4.75 & 5.00 & 5.23 & 5.44 & 5.64 \\
\hline Road crossfall (\%) & 3.00 & 3.00 & 3.00 & 3.00 & 3.00 & 3.00 & 3.00 & 3.00 \\
\hline Road gradient $(\%)$ & 1.00 & 2.00 & 3.00 & 4.00 & 5.00 & 6.00 & 7.00 & 8.00 \\
\hline Width of roadway $(\mathrm{m})$ & 20.80 & 20.80 & 20.80 & 20.80 & 20.80 & 20.80 & 20.80 & 20.80 \\
\hline Rainfall intensity $(\mathrm{mm} / \mathrm{h})$ & 80.00 & 80.00 & 80.00 & 80.00 & 80.00 & 80.00 & 80.00 & 80.00 \\
\hline Calculation results & & & & & & & & \\
\hline Flow path slope (\%) & 3.16 & 3.61 & 4.24 & 5.00 & 5.83 & 6.71 & 7.62 & 8.54 \\
\hline Flow path length (m) & 21.93 & 25.00 & 29.42 & 34.67 & 40.43 & 46.51 & 52.80 & 59.24 \\
\hline Flow depth (mm) & 3.84 & 4.00 & 4.20 & 4.41 & 4.62 & 4.82 & 5.00 & 5.18 \\
\hline
\end{tabular}


Table 4: $\quad$ Surface drainage calculations - 6-lane, 6-way rural roadway.

\begin{tabular}{|c|ccccccccc|}
\hline \multicolumn{7}{|c|}{ SURFACE DRAINAGE CALCULATIONS } \\
\hline 6 lane 2 way rural & & & & & & & & \\
roadway & & & & & & & \\
Road crossfall (\%) & 2.00 & 2.00 & 2.00 & 2.00 & 2.00 & 2.00 & 2.00 & 2.00 \\
Road gradient (\%) & 1.00 & 2.00 & 3.00 & 4.00 & 5.00 & 6.00 & 7.00 & 8.00 \\
Width of roadway (m) & 28.20 & 28.20 & 28.20 & 28.20 & 28.20 & 28.20 & 28.20 & 28.20 \\
Rainfall intensity (mm/h) & 80.00 & 80.00 & 80.00 & 80.00 & 80.00 & 80.00 & 80.00 & 80.00 \\
Calculation results & & & & & & & & \\
Flow path slope (\%) & 2.24 & 2.83 & 3.61 & 4.47 & 5.39 & 6.32 & 7.28 & 8.25 \\
Flow path length (m) & 31.53 & 39.88 & 50.84 & 63.06 & 75.93 & 89.18 & 102.65 & 116.27 \\
Flow depth (mm) & $\mathbf{4 . 9 4}$ & $\mathbf{5 . 3 0}$ & $\mathbf{5 . 7 0}$ & $\mathbf{6 . 0 8}$ & $\mathbf{6 . 4 3}$ & $\mathbf{6 . 7 5}$ & $\mathbf{7 . 0 4}$ & $\mathbf{7 . 3 1}$ \\
\hline Road crossfall (\%) & 2.50 & 2.50 & 2.50 & 2.50 & 2.50 & 2.50 & 2.50 & 2.50 \\
Road gradient (\%) & 1.00 & 2.00 & 3.00 & 4.00 & 5.00 & 6.00 & 7.00 & 8.00 \\
Width of roadway (m) & 28.20 & 28.20 & 28.20 & 28.20 & 28.20 & 28.20 & 28.20 & 28.20 \\
Rainfall intensity (mm/h) & 80.00 & 80.00 & 80.00 & 80.00 & 80.00 & 80.00 & 80.00 & 80.00 \\
Calculation results & & & & & & & & \\
Flow path slope (\%) & 2.69 & 3.20 & 3.91 & 4.72 & 5.59 & 6.50 & 7.43 & 8.38 \\
Flow path length (m) & 30.37 & 36.11 & 44.05 & 53.21 & 63.06 & 73.32 & 83.84 & 94.54 \\
Flow depth (mm) & $\mathbf{4 . 6 7}$ & $\mathbf{4 . 9 2}$ & $\mathbf{5 . 2 2}$ & $\mathbf{5 . 5 3}$ & $\mathbf{5 . 8 2}$ & $\mathbf{6 . 0 9}$ & $\mathbf{6 . 3 4}$ & $\mathbf{6 . 5 7}$ \\
\hline Road crossfall (\%) & 3.00 & 3.00 & 3.00 & 3.00 & 3.00 & 3.00 & 3.00 & 3.00 \\
Road gradient (\%) & 1.00 & 2.00 & 3.00 & 4.00 & 5.00 & 6.00 & 7.00 & 8.00 \\
Width of roadway (m) & 28.20 & 28.20 & 28.20 & 28.20 & 28.20 & 28.20 & 28.20 & 28.20 \\
Rainfall intensity (mm/h) & 80.00 & 80.00 & 80.00 & 80.00 & 80.00 & 80.00 & 80.00 & 80.00 \\
Calculation results & & & & & & & & \\
Flow path slope (\%) & 3.16 & 3.61 & 4.24 & 5.00 & 5.83 & 6.71 & 7.62 & 8.54 \\
Flow path length (m) & 29.73 & 33.89 & 39.88 & 47.00 & 54.81 & 63.06 & 71.59 & 80.31 \\
Flow depth (mm) & $\mathbf{4 . 4 8}$ & $\mathbf{4 . 6 6}$ & $\mathbf{4 . 8 9}$ & $\mathbf{5 . 1 4}$ & $\mathbf{5 . 3 8}$ & $\mathbf{5 . 6 1}$ & $\mathbf{5 . 8 3}$ & $\mathbf{6 . 0 3}$ \\
\hline
\end{tabular}

the Drainage Manual, Chapter 5 - Surface Drainage [5] with a rainfall intensity of $80 \mathrm{~mm} / \mathrm{h}$ used and the roadway width in accordance with SANRAL Geometric Design Guidelines, Chapter 4 - Design Elements analysed.

This may involve an update to supercede the current criteria published in the Drainage Manual [5] as well as minimum cross slope (superelevation) recommendation of $2.5 \%$ in the SANRAL Geometric Design Guidelines [4].

On the basis of the work done on the research paper, a number of additional items warrant further study and is recommended for South African conditions.

These include:

1. Full-scale skid resistance studies;

2. The relationship between water film thickness and hydroplaning potential;

3. The effect of water infiltration into pavement surface cracks;

4. Loss of water by splash and spray (need to be accounted for in the prediction of water film thickness);

5. Surface irregularities, especially rutting; and

6. Field trials to confirm alternative pavement surfacing and textures.

We need to design safer roads.

\section{References}

[1] South African Government Information, 11 January 2011, 'Address at the handover of the Torch of Peace and release of the 2010/11 Road Traffic 
Statistics'. Department of Transport Offices, Pretoria by $\mathrm{Mr}$ Sibusiso Ndebele, MP Minister of Transport.

[2] Politicsweb, 16 January 2012, '1,230 fatal crashes during festive seasonAddress at the Release of the 2011/12 Festive Season Road Traffic Statistics'. Department of Transport Offices, Pretoria by $\mathrm{Mr}$ Sibusiso Ndebele, MP Minister of Transport. www.politicsweb.co.za

[3] Tolmie, N. 2007. 'Road Safety in Relation to Speed on the N3'. Mobility. N3 Toll Concession (Pty) Ltd. South Africa.

[4] Tolmie, N. 2008. 'Message from Neil Tolmie CEO of N3TC'. Mobility. N3 Toll Concession (Pty) Ltd. South Africa.

[5] Committee of State Road Authorities 1988, 'TRH17 - Geometric Design of Rural Roads'. Technical Recommendation of Highways published by Division of Roads and Transport Technology, CSIR. Pretoria, South Africa.

[6] South African National Roads Agency Limited 2002, 'Geometric Design Guidelines'. Compiled by CSIR, Pretoria, South Africa.

[7] South African National Roads Agency Limited 2007, 'Drainage Manual'. 5th ed. Pretoria, South Africa.

[8] US Department of Transportation 1979. 'Design of Urban Highway Drainage'. Publication No. FHWA-TS-79-225. Federal Highway Administration. United States of America.

[9] US Department of Transportation 2009. 'Urban Drainage Manual'. Publication No. FHWA-NHI-10-009. Federal Highway Administration, Hydraulic Engineering Circular No. 22., 3rd ed. United States of America.

[10] Oakden, G.J. 1977, 'Highway Surface Drainage - Design Guide for Highways with a Positive Collection System'. Transit New Zealand. Roading Directorate - Ministry of Works and Development. New Zealand.

[11] Transportation Research Board of the National Academies 2009, 'Superelevation Criteria for Sharp Horizontal Curves on Steep Grades'. Research in Progress [Online]. Available from: http://www.trb.org/TRBNet /ProjectDisplay.asp?ProjectID=2720. [Accessed 17 November 2009].

[12] American Society of State Highway and Transportation Officials 2004, 'A Policy on Geometric Design of Streets and Highways'. 5th edn. Washington DC, United States of America.

[13] Bateman, B. 2008, 'Wet weather causes a spike in road accidents'. Pretoria News. South Africa.

\section{Additional literature references}

Anon. 'Road Safety on Van Reenen's Pass'. Road Freight Association. South Africa.

Olivier, J. J. 2008. 'Congestion on Van Reenen's Pass and the Construction of De Beer's Pass'. University of Pretoria, pp 4. Pretoria, South Africa.

Chaithoo, D. 2010. 'N3 Routine Road Maintenance Audit Report - JanuaryFebruary 2010'. Independent Engineer. Aurecon SA (Pty) Ltd. Hatfield, Pretoria, South Africa. 